\title{
A brief review on a traditional herb: abrus precatorius (L.)
}

\author{
Anamika Das ${ }^{1, *}$, Vernika Jain ${ }^{2}$, Amarnath Mishra ${ }^{3}$ \\ Amity Institute of Forensic Sciences, Amit University, Noida, Uttar Pradesh
}

*Corresponding Author:

Email: anamikasingh.07.01@gmail.com

\begin{abstract}
Abrusprecatorius is commonly known as Gunja or Jequirity belonging to Fabaccae- a pea family, abundantly found all throughout the plains of India, from Himalaya down to Southern India and Ceylon. The plant is considered as a valuable source of unique natural products for development of medicines against various diseases. The roots, seeds and leaves are used in traditional folklore medicine. Much research work has been conducted on Abrusprecatorius. The pharmacological studies have shown that Abrusprecatorius possesses a number of biological activities such as anti-bacterial, anti-cancer, anti-diabetic, antifertility, nehroprotective, anti-seratonergic, etc. As this plant has some potential medicinal value, it has some toxic effect too due to presence of "abrin" component which is fatal to human being. The present review represents the nature, pharmacological actions, chemical constituents, toxicity and forensic significance related to Abrusprecatorius.
\end{abstract}

Keywords: Toxicology, Chemical composition, Pharmacological activity, Toxic effect, Photochemical analysis, Analytical techniques, Forensic significance.

\section{Introduction}

Abrus precatorius (L.) is a popular plant belonging to the family of fabaceae (Leguminosae)- pea family. ${ }^{(1)}$ It is native to India widespread in tropical and subtropical areas, at altitudes up to $1200 \mathrm{~m}$ on the outer Himalayas of India. It is a beautiful, much-branched, slender, perennial, deciduous, woody, prickly twining or climbing herb. Stem cylindrical, wrinkled, bark smooth-textured, brown. The leaves are pinnate and glabrous, with many leaflets (12 or more) arranged in pairs. The leaflets are oblong, measuring 2.5-cm long and $1.5-\mathrm{cm}$ wide. ${ }^{(3)}$ Flowers are numerous and appear in the leaf axils along the stems, shorter than leaves, fascicled on the swollen nodes and occur in clusters 1 to 3 inches long, usually red to purple, or occasionally white. The plant produces stout and short brownish pods, which curl back on opening to reveal pendulous red and black seeds, 4 to 6 peas in a pod. ${ }^{(2)}$ The fruit is a legume (pea shaped pod) about $3 \mathrm{~cm}$ long containing hard ovoid seeds about $1 \mathrm{~cm}$ long.

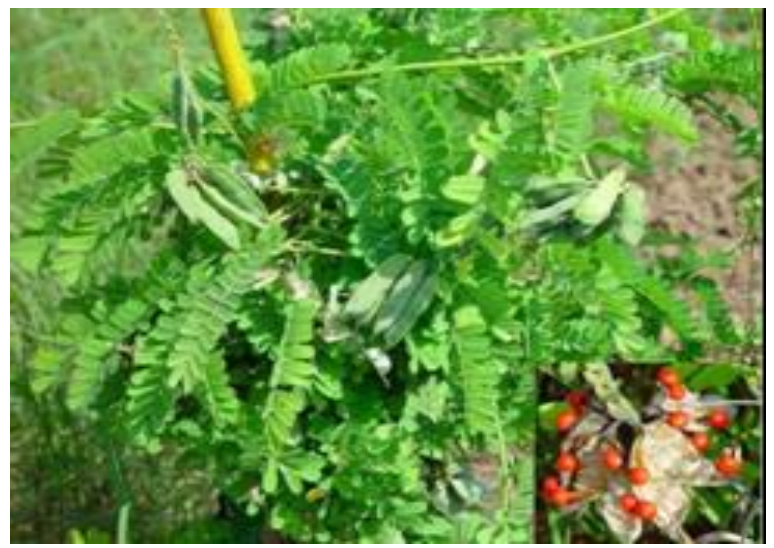

Fig. 1: Picture of Abrusprecatorius herb ${ }^{(3)}$

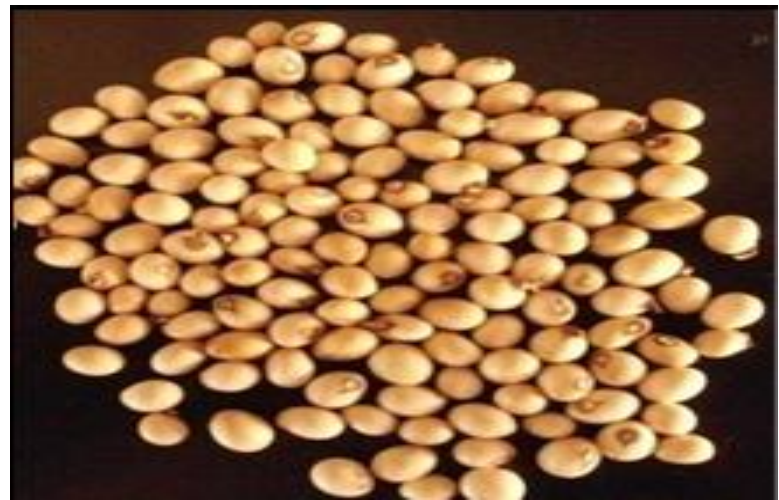

Fig. 2: Abrusprecatorius seeds ${ }^{(12)}$

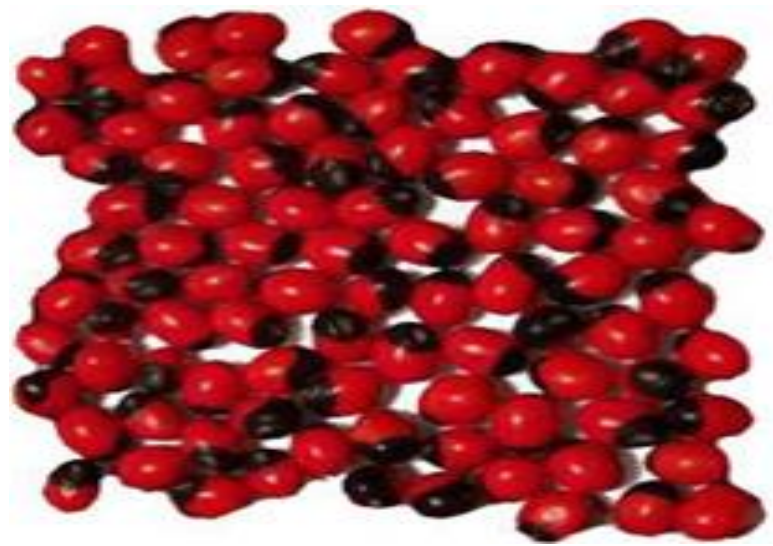

Fig. 3:Red Abrusprecatorius seed ${ }^{(6)}$

Plant Profile: Taxonomical classification-(2)

Kingdom: Plantae

Division: Magnoliophyta

Order: Fabales

Family: Fabaceae

Subfamily: Faboideae

Genus: Abrus 


\section{Species: Abrus precatorius}

In India it is known by several names like Gunj (Marathi); Ganchi, Gunchi, Rati (Hindi); Chunhali, Kunch (Bengali); Chanothi, Gunja(Gujarati); Ganji, Gul-Ganju, Guluganji, Madhuka(Karnataka); Kunni, Guruginia, Guruvenda (Telugu); Kunnikuru (Malayalam); Chanoti, Gunchi, Gunja (Marathi); Gundumani, Kuntumani (Tamil); Gunja, Runji (Oriya) Liluwani, Raturmani (Assam); Labrigunchi, $\operatorname{Ratak}\left(\right.$ Punjab). ${ }^{(2)}$

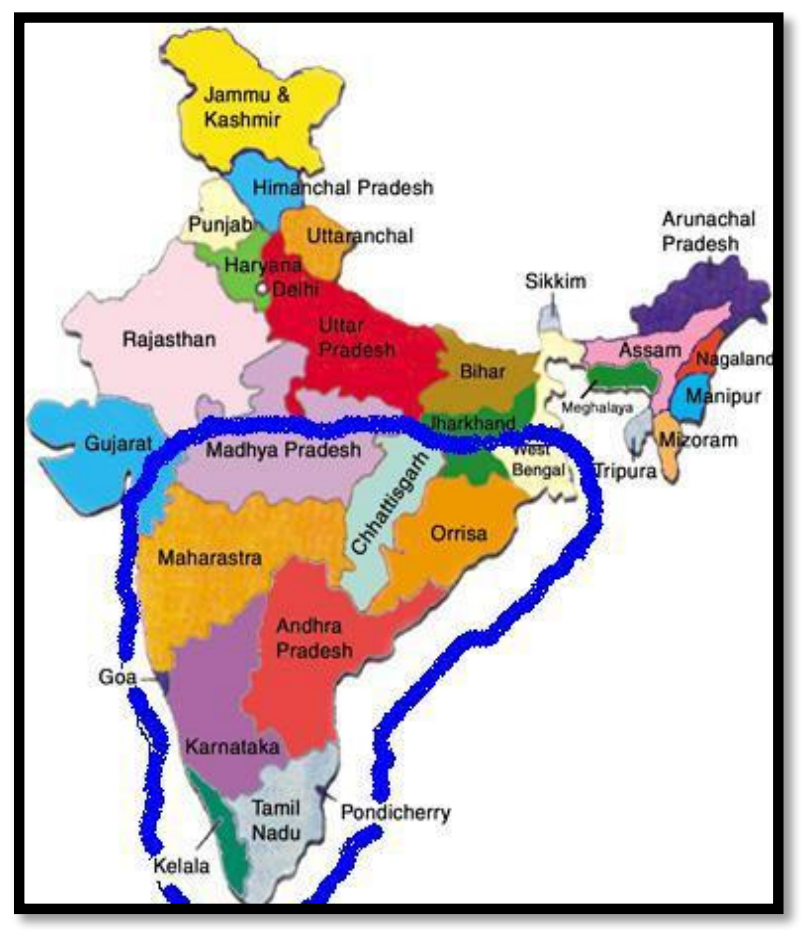

Fig. 4: -A. precatoriu $L$. - Seeds Tropical areas of India *as marked in blue Boundary in the Map ${ }^{(5)}$

Chemical Composition: Abrus pre-catorius is rich in various chemical constituents such as abrasine, abrol, precol and pre-casine from the roots. The active principle in the seeds of A. precatorius is abrin. Seeds are rich in several essential amino acids like alanine, serine, choline, valine, and methyl ester. ${ }^{(3)}$ The seeds contain the protein toxin, abrin which is deadly when ingested even at a small dose. It was reported that as minute as $0.00015 \%$ of toxin per body can cause fatality in humans. They contain poisonous protein, a fat-splitting enzyme, aglucosideabrussic acid, haemagglutinin, albuminous substance named abrin and a quantity of ureas. Ions likecalcim, magnesium, sodium, potassium, etc. ${ }^{(5)}$ The seeds yielded a mixture of stigmasterol and $\beta$-sitosterol in a 4:1 ratio, while the peduncle afforded triglyceride.
Chemical analysis of seed:(2)

\begin{tabular}{|l|l|}
\hline \multicolumn{1}{|c|}{ Component } & \multicolumn{1}{|c|}{ Value } \\
\hline Nitrogen & $6.272 \%$ \\
\hline Crude protein & $39.20 \%$ \\
\hline Crude fibre & $9.08 \%$ \\
\hline Carbohydrates & $42.42 \%$ \\
\hline $\begin{array}{l}\text { Water soluble carbohydrates } \\
\text { (at room temperature) }\end{array}$ & $\begin{array}{l}9.91(\mathrm{~g} \text { glucose/100 g } \\
\text { seed) }\end{array}$ \\
\hline $\begin{array}{l}\text { Water soluble carbohydrates } \\
\text { (At 1000C temp.) }\end{array}$ & $\begin{array}{l}18.72(\mathrm{~g} \text { glucose/100 g } \\
\mathrm{seed})\end{array}$ \\
\hline $\begin{array}{l}\text { Total soluble reducing } \\
\text { substances (at room } \\
\text { temperature) }\end{array}$ & $\begin{array}{l}2.18(\mathrm{~g} \text { glucose } / 100 \mathrm{~g} \\
\text { seed) }\end{array}$ \\
\hline $\begin{array}{l}\text { Total soluble reducing } \\
\text { substances } \\
\text { (At 1000C temp.) }\end{array}$ & $\begin{array}{l}2.43(\mathrm{~g} \text { glucose/100 g } \\
\text { seed) }\end{array}$ \\
\hline
\end{tabular}

The leaves were found to contain sweet tasting compounds such asabrusoside and glycyrrhizin, which are sweeter than sucrose and have lower caloric value. ${ }^{(2)}$ Abrusoside A-D, which contains abrusogenin as aglycone, which has sweetness potencies 30-100 times greater than that of sucrose ${ }^{(3)}$ A number of triterpenes were isolated from A. precatorius L., abrusoside A-E and abrusogenin. ${ }^{(4)}$ In a study, new compound has been isolated from the dichloromethane extract of the leaves of Abrusprecatorius which is known as Pterocarpan or 2,3,4,8-tetramethoxy-6a,11a-dihydro-6Hbenzo[4,5]furo[3,2-c]chromene-7,9-diol. ${ }^{(14)}$

Glycyrrhizin: As the roots and leaves of Abrus precatorius contain glycyrrhizin. ${ }^{(23)}$ Glycyrrhizin is an important phytoconstituent of liqorice 24 which is widely used in the pharmaceutical and food industry. ${ }^{(24)}$

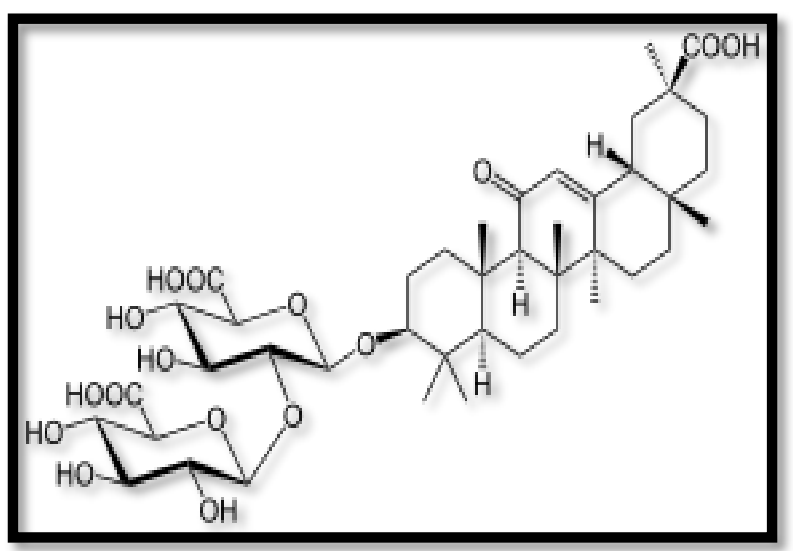


Glycyrrhizin: ${ }^{(24)}$ Root of this plant also containAbrol, abrasine, precasine, precol and some proteins like abraline, abricin, delphinidin, gallic-acid, picatorine. Triterpenoids and saponins, glycyrrhizinandoleanolic acid are found in the root and abrusosides a, b, c, d.

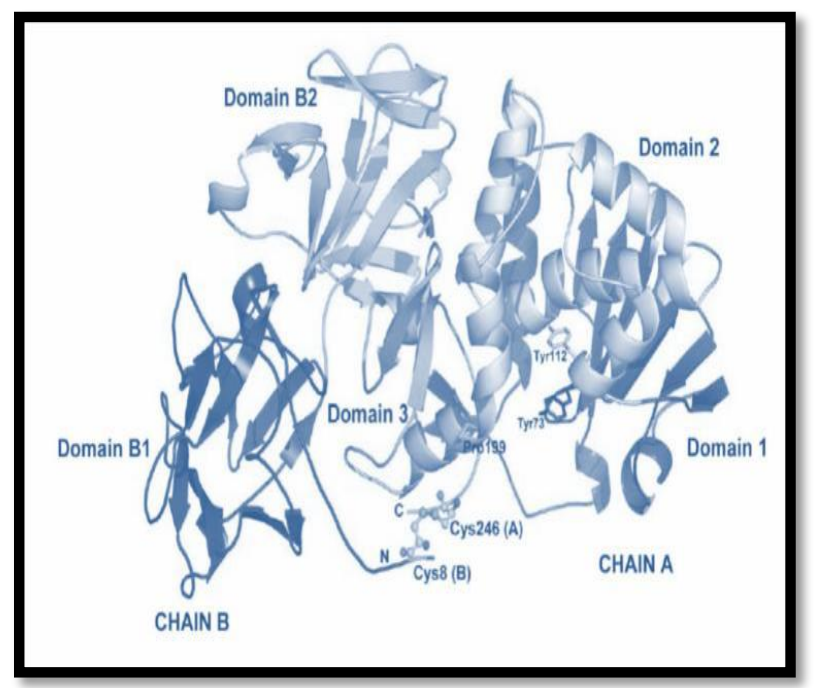

Fig. 5: Protein data bank structure of agglutinin.

\section{Pharmacological Activity}

It is a medicinal herb whose leaves, roots and seeds are used for various purposes. Gunja is one such drug that under goes the process of sodhana prior to its use as a medicine in ayurveda ${ }^{(7)}$ to treat scratches and sores and wounds caused by dogs, cats and mice, and is also usedwith other ingredients to treat leukoderma. The plant Abrus precatorius is used in Ayurveda, Homeopathy, Folk, Tibetian, Sidha, and Unani. Its leaves are used as nerve tonic, applied on swellings and cuts and mouth ulcer. Abrus precatorius is also used as an abortifacient, laxative, sedative and aphrodisiac. ${ }^{(15)}$ The roots are used for gonorrhoea, jaundice and haemoglobinuric bile. The oil extracted from seeds is said to stimulate the growth of human hair. The leaves are used for their anti-supportive properties. The plant contains glycyrrhizin as an active phytoconstituents. ${ }^{(24)}$

Antimicrobial Activity: Antimicrobial activity of divergent parts of Abrusprecatorius like roots, leaves and seeds were studied against some of the microorganism. Root extract of Abrus precatorius against the Gram positive organism Staphylococcus aureus was found to be active. Root extracts possess good antibacterial potential particularly against Staphylococcus aureus. An antimicrobial activity of Abrus precatorius seed extract was assayed by in vitro studies in agar well diffusion method against ten bacterial species. Methanol extract exhibited antibacterial activity towards almost all the bacterial microorganisms. ${ }^{(1)}$ It was considered that if the extracts displayed an MIC less than $100 \mu \mathrm{g} / \mathrm{ml}$, the antimicrobial activity was good; from 100 to $500 \mu \mathrm{g} / \mathrm{ml}$ the antimicrobial activity was moderate; from 500 to
$1000 \mu \mathrm{g} / \mathrm{ml}$ the antimicrobial activity was weak; over $1000 \mu \mathrm{g} / \mathrm{ml}$ the extract was considered inactive. Thus, the antimicrobial activity of the root extract is moderate. ${ }^{(2)}$

Anti-diabetic activity: The anti-diabetic effect of chloroform-methanol extract of $A$. precatorius seed i.e. $50 \mathrm{mg} / \mathrm{kg}$ was examined in alloxan diabetic rabbits. The percentage reduction of blood glucose after treatment with chloroform - methanol extract at different intervals shows that the chloroform - methanol extract of Abrus precatorius seed has anti-diabetic properties having Trig one line which was similar to that of chlopropamide. Different observation was found in another study on rat model after treated with Ethanol/water (1:1) extract of the aerial parts of Abrus precatorius at a dose of $250 \mathrm{mg} / \mathrm{kg}$ which was shown to reduce only $30 \%$ blood sugar level. ${ }^{(5)}$ The chloroform methanol extract of Abrusprecatorious was able to reduce alloxan hyperglycaemic blood glucose levels. The extract was seen to be slightly influential than chlorpropamide, known anti-diabetic drug of sulfonylurea class. The potency was measured in terms of longer time of action and higher percentage reduction in blood glucose levels. Many bioactive substances have been isolated from plants which have been used as antidiabetic agents. ${ }^{(2)}$

Anti-fertility activity: Testicular degeneration was characterized by reduced number of cells in the epithelium along with reduction in the number of sperm cells was noted when the aqueous extract of Abrusprecatorious was administered to male rats for 18 days at doses of $400 \mathrm{mg}, 800 \mathrm{mg}$ and $1600 \mathrm{mg} / \mathrm{kg}$ body weight. The alcoholic seed extracts of Abrusprecatorious for 60 days at a dose of $100 \mathrm{mg} / \mathrm{kg}$ body weight significantly lowered cauda epididymal sperm motility and brought about a drop in the levels of succinate dehydrogenase and ATPase in the sperm of albino rats. Scanning electron microscopic studies on sperm morphology revealed acrosomal damage, decapitation and formation of bulges on the midpiece region of sperms following exposure to Abrusprecatorious seed extracts. Dose dependent reduction in testicular weight, sperm count and degeneration in later stages of spermatogenesis were found in the testis of rats treated with steroidal fraction of seeds. Irreversible impairment of the motility of human spermatozoa at a concentration of $20 \mathrm{mg}$ per $\mathrm{mL}$ of the methanol extract of Abrusprecatorious seed extracts was reported, which may be due to the decrease in cAMP and enhanced generation of reactive oxygen species. According to Sinha, steroidal fraction has been isolated from the seeds of Abrusprecatorius and found to exhibit antifertility activity. It promote post-testicular antifertility effects and suppressed sperm motility in cauda epididymis. As far as evaluation of DNA damage by $A$. precatorius is concerned, it has been demonstrated that isolated constituents from the seeds 
of A. precatorius that is, agglutinin, abrin induce apoptosis by causing DNA fragmentation in vitro. ${ }^{(2)}$

Tumor inhibiting activity: There is another finding reported about water extract of fresh seeds at a concentration of $2.0 \mu \mathrm{l} / \mathrm{ml}$ was inactive against mitogenic activity on human lymphocytes. Similar results were reported of methanol extract at $10 \mathrm{mg} / \mathrm{ml}$ on Salmonella typhimurium TM677 and ethanol (95\%) extract of dried stem $(30.0 \mathrm{mcg} / \mathrm{ml})$ against CA-9KB, ED50. Another two extracts (water and methanol) of dried seeds give promising results on Sarcoma Yoshida ASC and cell culture strain CA-9KB. Water extract of seeds was active on the testes of Poecilocera picta. The isolated compound abrin from the seeds of Abrusprecatorius showed in vitro and in vivo antitumor properties by the induction of apoptosis-. Negative results were obtained on virus-avian myeloblastosis at IC50 > $1000 \mathrm{mg} / \mathrm{ml}^{(3)}$

Anti-allergic activity: Abruquinones A, B, D and F showed strong anti-allergic effects. Inhibition of superoxide formation was less than $0.3 \mu \mathrm{g} / \mathrm{ml}$ from rat neutrophils and less than $1 \mu \mathrm{g} / \mathrm{ml}$ for histamine from mast cells. Polymyxin B-induced hind paw oedema was suppressed by abruquinone A, in normal as well in adrenalectomised mice. Histamine, bradykinin, serotonin and substance P-induced plasma extravasation in ear oedema was also repressed to a greater extent than with diphenhydramine and methysergide. The wound healing activity of red and black colored seed of and methanol insoluble fractions of white form resulted in early wound healing activity which may be due to the presence of gums, mucilages, tannins or phenolic compounds in the seeds. This support the effectiveness of the seed extracts and fraction in controlling the infection in vivo. ${ }^{(3)}$

Anti-inflammatory activity: The anti-inflammatory activity of Abrus precatorius extract was investigated on inflammation induced by croton oil on rat ear model. Extract of Abrus precatorius when co applied with croton oil to the rat ear resulted in the reduction of inflammatory response (observed after 6 hours compared with croton oil alone). The extract produced $2 \%$ reduction of the inflammatory response in croton oil alone group which explains the usefulness of the leaves of this plant in the treatment of inflammatory disease conditions by traditional healers. ${ }^{(3)}$

Antispermatogenic effect: Ethanol extract of seeds, administered intragastrically to male ratsfor 60 days at a dosage of $100.0 \mathrm{mg} / \mathrm{kg}$, was inactivewhile the ethanol/water (1:1) extract of dried seeds, administered bygastric intubation to rats at a dosage of $250.0 \mathrm{mg} / \mathrm{kg}$, was vital. Although no significant histologic changes in the testes were reported, sperm concentration was reported to be significantly decreased in both cauda epididymis and testes after dosing for 60 days. Sterol fraction of dried seeds administered intramuscularly to rats was active. Testicular lesions which were marked by the cessation of spermatogenesis and a remarkable reduction in the diameter of the seminiferous tubules were also noted. ${ }^{(1)}$

Bronchodilator activity: A traditional immunological model of antigen induced airway obstruction is the histamine induced broncho-constriction. Histamine when inhaled causes hypoxia which leads to convulsion in the guinea pigs and causes very strong and smooth muscle contraction, profound hypotension, and capillary dilation in the cardiovascular system. A prominent effect caused by histamine is severe bronchoconstriction in the guinea pigs which causes asphyxia and fatality. Bronchodilators can delay the occurrence of these symptoms. Salbutamol with bronchodilator activity is a well known $\beta$-2-receptor agonist and is routinely used in the management of conditions of broncho-constriction as occurs in asthma. The results suggest that the Abrus precatorius leaf extract may have bronchodilator activity justifying the traditional uses of the plant in the management of asthma. Hence a decrease or inhibition of the contractions induced by histamine and or acetylcholine in the presence of the leaf extract of Abrus precatorius, is suggestive of possible anti-histaminic or anticholinergic activity. The methanolic extract of the leaves of Abrus precatorius has broncho-dilatory effect and its use traditionally in the management of asthma. ${ }^{(17)}$

Anti-arthritic activity: The anti arthritic activity was studied on croton oil induced inflammation rat model. Two different concentration (200 and 400mg/kg) of water extract of leaves of Abrus precatorius were administered orally and both the extracts showed reduction in paw inflammation. Another study reported about white (APW) and red (APR) seed extracts of Abrus precatorius on Freund's complete adjuvant induced arthritis in rats. It was observed that the APW significantly $(p<0.001)$ inhibited the FCA induced arthritis and increased paw withdrawal latency indicating a protective effect against arthritis but in case of APR, the inflammation was suppressed at significant level $(\mathrm{p}<0.05)$ at the later phase. ${ }^{(3)}$ APW treatment found to possess anti-arthritic activity significantly inhibited the development phase of arthritis, which is further supported by its radiographic analysis. It is interesting to note that APW treatment was found to be more effective and exhibited significant $(\mathrm{p}<0.001)$ anti arthritic activity against adjuvant-induced arthritis experimentally with less toxicity (no ulcerogenic), compared to APR treatment. ${ }^{(2)}$

Immunomodulating activity: The immunomodulating activity was done by various researchers and one of the activities reported the effect of abrin on the cellular immune responses in normal and tumor-bearing animals. In a study, Natural killer cell activity was enhanced significantly by abrin in both the normal (49.8\% cell lysis on day 9$)$ and the tumor-bearing group (51.7\% cell lysis on day 9$)$, and it was found to be earlier than the control. Antibody dependent cellular 
and complement mediated cytotoxicity was also enhanced in the abrin treated tumor-bearing group on the ninth day (44\% cell lysis) as well as 15 day ((27.6\% cell lysis) which confirmed the immunomodulatory property of abrin. Another study reported about the activity of abrus agglutinin on native (NA) and heat denatured (HDA) condition for murinesplenocyte proliferation, cytokine secretion, NK-cell activation, and thymbocyteproliferationin. Native agglutinin and HDA induced conditioned media of non-adherent splenocytes could stimulate adherent splenocytes and vice versa. Heat denatured agglutinin has ability to activate NK-cell at much lower concentration than that of NA, but the extent of NK-cell activation was higher for NA. Proliferation of thymocytes by NA and HDA was also observed. This study indicates that abrus agglutinin could be a potential immunomodulator both in native as well as in heat denatured form. A non-toxic dose of abrin, (1.25 mg/kg body wt) consecutively for five days in normal mice stimulated specific humoral responses. Increasing in number was observed in total leucocyte count, weights of spleen, thymus, circulating antibody, antibody forming cells, bone marrow cellularity and alpha-esterase positive bone marrow cells. The results suggest that abrin can potentiate the humoral immune response of the host. In vitro immunostimulatory effect of abrus lectins derived peptide fractions was investigated and both AGP and $\mathrm{ABP}$ act as immunostimulants in vitro in DL bearing mice. $^{(3)}$

Immunstimulatory effects: Abrin B derived from seeds of A. precatorius causes a strong agglutination of cells. This agglutination increases according to the order of differentiation in cells. A non toxic dose of abrin $(1,25 \mu \mathrm{gram} / \mathrm{kg}$ body weight $)$ can potentiate an immunresponse of a host, like increase in total leucocytes, weights of thymus and spleen. ${ }^{(6)}$

Memory enhancer activity: Abrus precatorius has been studied in Alzheimer's disease model by identification of glycohistochemically the microglial cells (MGC) activation in autoptic brain samples. Abrus precatorius agglutinin recognizes MGC in the cerebral white matter showed rod-like cells and appear to be particularly dense in those areas proximal to an oligodendroglial cell. Active constituent lectin from Abrus precatorius plant has been used to histochemically identify the microglial cells activation in autopic brain samples from Alzheimer's disease subjects. ${ }^{(3)}$
Anti-cancer Activity: The in-vitro activity the aqueous extract of abrusprecatorius leaves could be potentially useful for the development of therapeutic agents against murinmestocytoma cells. In a study, the aqueous extract was evaluated as a promising anticancer solution using MTT assays. The result given by Mohammed Shafi Sofi the aqueous extract of abrusprecatorius leaf exhibits anticancer activity against human breast cancer cell line MDAMB-231 with IC50 $=98 \mu \mathrm{g} / \mathrm{mL}$. Many studies on different panels of cancer cell lines, describe that wide bioactive phytocompounds isolated from abrusprecatorius including tannins, alkaloids, steroids, saponins, terpenoids, and flavonoids demonstrated marked inhibitory effects and have properties to induce apoptosis on various types of cancer. ${ }^{(16)}$

Antioxidant and Anti-proliferative: The leaf extract of abrusprecatorius have the ability to function as an antioxidant agent using in vitro assays. The extracts of this plant also contain significant amount of flavonoids which have recently attracted medicinal attention as bioactive agents. They have been ascribed to have resilient antioxidant activity and helps to protect cells against oxidative damage caused by free radicals due to their redox properties, which allow them to act as reducing agents, singlet oxygen quenchers and hydrogen donors.

The anti-proliferative effects were quantified in terms of cytotoxicity i.e. percentage inhibition and IC50 values were also determined. The lower the value of IC50, higher is the anti-proliferative activity. In a study, it has been demonstrated that the Abrusprecatorius leaf extracts(APA and APE) are potential anti-proliferative agents without any toxic effect on normal cells. The antioxidant and anti-proliferative activities might be due to the synergistic actions of bioactive compounds. Therefore, the plant has promising compounds to be tested as potential antioxidant drugs for treatment of diseases resulted from oxidative stress. ${ }^{(18)}$

Other Uses: The brightly-coloured seeds attract children; they also play with them and in school use them in their handiwork and to count. Necklaces and other ornaments are made from the seeds and worn by both children and adults. ${ }^{(15)}$ Leaves and seeds are nutritious. Boiled seeds are eaten in certain parts of India. It is claimed that cooking destroys the poison of seeds. The small seeds are used in jewellery. They have a uniform weight of 1/10th of a gram, hence used as weighing unit. Seeds have also the potential of good insecticide and antimicrobial activity. ${ }^{(6)}$ 


\begin{tabular}{|l|l|l|}
\hline \multicolumn{1}{|c|}{ Part of the plant } & \multicolumn{1}{c|}{ Type of Extract } & \multicolumn{1}{c|}{ Activity } \\
\hline Roots, seeds and leaves & Methanol and petroleum ether & Antibacterial Activity \\
\hline Seeds & Petroleum ether & Anticancer activity \\
\hline Seeds & chloroform - methanol extract & Anti diabetic effect \\
\hline Seeds & ethanolic extract aqueous extract & Anti-fertility activity \\
\hline Leaves & water extract & Anti-inflammatory activity \\
\hline Seeds & $\begin{array}{l}\text { hexane, chloroform, methanol } \\
\text { and water }\end{array}$ & Anti-microbial activity \\
\hline Seeds & ethanol & Anti-oxidant activity \\
\hline Seeds & aqueous extract & Nephroprotective activity \\
\hline Leaves & methanol & bronchodilator activity \\
\hline Red \&white seeds & Ethanol & Anti-arthritic activity \\
\hline Leaves & ethyl acetate & Antiserotonergic Activity \\
\hline Leaves & chloroform and ethanol & Cytotoxic property \\
\hline Shoot & methanol & larvicidal activity \\
\hline
\end{tabular}

\section{Toxic Effect}

Abrus precatorius seeds contain the toxic lectins, namely abrin (ABR)A-D and the relatively less toxic agglutinin known as Abrus agglutinin (AGG). Abrin is a $63 \mathrm{kD}$ heterodimeric glycoprotein, but agglutinin is a heterotetrameric glycoprotein having molecular weight of $134 \mathrm{kD}$. Both of these lectins belong to the ribosome inactivating proteins-II (RIP-II) family, and consist of a toxic subunit A chain (molecular weight $30 \mathrm{kD}$ ) (Lin EY et al, 2004) a galactose-binding $B$ subunit (molecular weight $31 \mathrm{kD}$, (Lin EY et al, 2004) connected by a single disulfide bond (Olsnes et al, 1974). Abrins immobile the protein biosynthesis by inhibiting the 60S-ribosomes of animal cells, permanently. The protein synthesis inhibitory concentration for Abrus agglutinin is (IC50=3.5 nM) is weaker than Abrin. Abrin-a, one of four isoabrins from the plant, has the highest inhibitory effect on protein synthesis and consists of an A chain of 250 amino acids and a B chain of 267 amino acids (Tahirov, Lu \&Liaw 1994).(27) Decreased toxicity of Abrus agglutinin than abrin is due to substitution of Asn200 in abrin-A with Pro199 in agglutinin, though the overall protein folding of agglutinin-I is similar to that of abrin. ${ }^{(12-13)}$

Fatal incidents have been reported following ingestion of well-chewed seeds of Abrus precatorius. Because of its hard seed coat, it can pass through the gastrointestinal tract undigested and remain harmless. The unripe seed has a soft and easily broken seed coat and is thus more dangerous. It has been reported that poisoning has been experienced through a finger prick when stringing the seed. Symptoms may develop after a few hours to several days after ingestion. They include severe gastroenteritis with pronounced nausea and vomiting. Mydriasis will occur, as well, as muscular weakness, tachycardia, cold sweat, and trembling. There is no known physiological antidote. ${ }^{(13)}$

\section{Phytochemical Analysis}

Collection of sample: The Plants were collected and chopped into small pieces, shade dried and coarsely powdered. ${ }^{(6)}$

Preparation of extracts: The powdered sample obtained was subjected to successive extraction with methanol and distil water by Soxhlet method. The extracts were collected and distilled off on a water bath at atmospheric pressure and the last trace of methanol solvent was removed. The resulted extracts were used for preliminary phytochemical screening. ${ }^{(6)}$

According to the methods adopted by Peach and Tracey (1955), Niazi (1972), Balbaa et al. (1976) and Abu-Shaweish (1981) the extracts of each powder were subjected to the following tests: ${ }^{(19)}$

1. Tests of Alkaloids: Ten grams of the seed powder was extracted with $50 \mathrm{ml}$ of dilute $\mathrm{HCl}$. The acidic extract was filtered, rendered alkaline with dilute $\mathrm{NH}_{4} \mathrm{OH}(0.1 \mathrm{~N})$, and then extracted with $\mathrm{CHCl}_{3}(3$ x $20 \mathrm{ml}$ ). The combined chloroform extracts were 
evaporated to dryness and the residue was redissolved in $1 \mathrm{ml}$ of dilute $\mathrm{HCl}$.

If the color of the solute change into white turbidity with Mayer's reagent (Potassium Mercuric Iodide), brown precipitate with Wagner's reagent (iodine potassium iodide solution) or orange color with Dragendorffs reagent (potassium bismuth iodide), this indicates the presence of alkaloids. ${ }^{(19)}$

\section{Test for Flavonoids:}

a. Alkaline Reagent Test: Dried seed powder (5 g) were macerated overnight in $150 \mathrm{ml}$ of cold $1 \%$ $\mathrm{HCl}$ and filtered. Ten milliliters of the filtrate were alkalinized with $\mathrm{NaOH}$. The formation of a yellow color indicates the presence of flavonoid compounds. ${ }^{(19)}$

b. Lead acetate Test: The Extract was treated with few drops of lead acetate solution. Formation of yellow colour precipitate indicates the presence of flavonoids.

3. Tests of Glycosides:

a. Keller Killiani Test: Test solution was treated with few drops of glacial acetic acid and Ferric chloride solution and mixed. Concentrated sulphuric acid was added, and observed for the formation of two layers. Lower reddish brown layer and upper acetic acid layer which turns bluish green would indicate a positive test for glycosides.

b. Borntrager's Test: To the $3 \mathrm{ml}$ of aqueous extract, dil. $\mathrm{H}_{2} \mathrm{SO}_{4}$ was added. The solution was then boiled and filtered. The filtrate was cooled and equal volume of benzene was added to it. The solution was shaken well and the organic layer was separated. Equal volume of dilute ammonia solution was added to the organic layer. The ammonia layer turned pink indicating the presence of glycosides. ${ }^{(6)}$

1) Test for Saponins: Sample was dissolved in normal saline solution. An aliquot $(5.0 \mathrm{ml})$ of the solution was added to $10 \mathrm{ml}$ of 1: 40 suspension of red blood corpuscles in normal saline solution and the solution was then added for 5 minutes to detect the presence of saponins through the observation of hemolysis. $^{(19)}$

2) Test for proteins and amino acids (ninhydrin test): To $0.5 \mathrm{~g}$ of extract, $0.25 \% \mathrm{w} / \mathrm{v}$ ninhydrin reagent was added and boiled for few minutes. Formation of blue colour indicates the presence of amino acid.

3) Test for starch (molisch's test): Two drops of alcoholic $\alpha$-naphthol solution was added to $0.1 \mathrm{~g}$ of extract in a test tube. Formation of the violet ring at the junction indicates the presence of starch. ${ }^{(22)}$

4) Test of Tannins: Two milliliters of bromine water were added to $5.0 \mathrm{ml}$ of the ethanolic extract of Abrusprecatorius seed. The development of colored precipitate was an indication of the presence of tannins.
5) Test of Resins: In a porcelain dish, $1 \mathrm{~g}$ of seed was mixed with $10.0 \mathrm{ml}$ acetic acid by the aid of gentle heat, then cooled and a drop of concentrated sulfuric acid was added carefully. A bright purplish red color was produced, which was changed to violet and then to brown in the presence of resins.

6) Test of Phenols: The Folin-Denis reagent was used to detect the phenolic compounds. Sample was dissolved in distilled water then $1 \mathrm{ml}$ of FolinDenis reagent was added. The development of a blue color indicates the presence of phenols (19).

\section{7) Test for phytosterols:}

a. Salkowski's test: The extract was dissolved in 2 $\mathrm{ml}$ chloroform in a test tube. Conc. Sulphuric acid was added carefullyon the wall of the test tube to form a lower layer. A reddish brown colour at the interface indicated the presence of a steroid ring i.e., glycoside.

b. Liebermann Burchard's test: The Extract was treated with chloroform and filtered. The filtrate was treated with few drops of acetic anhydride, boiled and cooled. Conc. Sulphuric acidwas added. Brown ring formed at the junction which indicates the presence of phytosterols. ${ }^{(6)}$

8) Test for anthraquinones: For this test, $0.5 \mathrm{~g}$ of extract was taken into a dry test tube and $5 \mathrm{ml}$ of chloroform was added and shaken for 5 mins. It was filtered and the filtrate shaken with equal volume of $100 \%$ ammonia solution. Pink, violet or red color in the ammoniacal layer (lower layer) indicates the presence of free anthraquinones.

\section{Analytical Techniques}

There are many techniques which are introduced to find out the chemical constituents which are present in Abrusprecatorius plant like chromatographic fingerprint technique to evaluate the quality of herbal samples or their derived products, chemical fingerprints using HPTLC,TLC is a rapidly developing technique that offers great potential for monitoring the quality of herbal substances, particularly for identifying a particular herb and distinguishing it from closely related species, High Performance Thin Layer Chromatography has emerged as one of the most effective tools in the last two decades for the separation and quantification of secondary metabolites especially for the evaluation of botanical materials ${ }^{(8)}$ and many more.

\section{HPTLC fingerprinting and IR spectra:}

a. An HPTLC fingerprint is suitable for rapid and simple authentication and comparison of subtle differences among samples of identical plant resource from different geographic locations. The chromatographic fingerprint developed for Abrusprecatorius plant represents a comprehensive qualitative approach for the purpose of authentication, ensuring the consistency, evaluation of quality and stability of 
leaves of Abrusprecatorius Linn. inherbal drugs and their related products. ${ }^{(9)}$ For Abrusprecatorius seed, red and white coloured samples were studied(Bapat and Sane, IJPSR, 2012; Vol. 3(3): 914-921). Detoxification was done by boiling seeds in triphalaquath for 3 hour in 'dolayantra' after separating the seed coat and also by keeping the 80 mesh powder of samples in hot air oven at $100^{\circ} \mathrm{C}$ for 1 hour 4 . It was found that for both the samples of seeds i.e. red and white, when compared with crude, there was not much difference in HPTLC pattern, when the samples were kept in oven for $1 \mathrm{hr}$ at $100^{\circ} \mathrm{C} 4$. The toxic protein abrin might be stable in crude form, while unstable in pure form when kept at $100^{\circ} \mathrm{C}$ for $1 \mathrm{hr}$.

b. Infra Red spectra of Abrusprecatorius seeds: Spectra were recorded in $\mathrm{KBr}$ pallets. The results of IR spectroscopy also supported the above conclusions. Spectra obtained in case of crude seeds and detoxified in oven were almost similar. While IR spectra in case of seeds treated with triphalaquath showed variation at functional group region of the spectra, at wavelength 2349 cm-1 for both red and white seeds of Abrusprecatorius. ${ }^{(9)}$

2. Nuclear Magnetic Resonance: Silica gel chromatography of the dichloromethane extract of the pericarp of Abrusprecatorius afforded abrusogenin, ${ }^{(1)}$ triglyceride and saturated monoglyceride. The seeds yielded a mixture of stigmasterol and $\square$-sitosterol in a 4:1 ratio, while the peduncle afforded triglyceride. The structure of 1 was elucidated by extensive 1D and 2D NMR spectroscopy. Literature search revealed that Abrusogenin as confirmed by similar $1 \mathrm{H}$ NMR and 13C NMR data. The structure of monoglyceride was elucidated by extensive $1 \mathrm{D}$ and 2D NMR spectroscopy and the structures of stigmasterol and $\beta$-sitosterol were confirmed by similar $1 \mathrm{H} \mathrm{NMR}$ and 13C NMR. ${ }^{(4)}$

3. Thin Layer Chromatography: Diluted samples of leaves of Abrusprecatorius were qualitatively measured by TLC, butanol: acetic acid: water (4:1:5) upper layer was used as mobile phase and TLC plates coated with silica gel were used as stationary phase. The plates were sprayed with $1 \%$ ethanolic 2- amino ethyl diphenyl borinate solution followed by $5 \%$ ethanolic solution of polyethylene glycol-400. Flavonoid appears in color zone under UV-365nm and standard flavonoids were used for identification with the retention time of 0.86 . With both reagent $\mathrm{A}$ and $\mathrm{B}$ light green color is obtained. The remaining extract was evaporated and residue was acquired, it was subjected to various physical and spectral analyses. ${ }^{(10)}$

Isolation and Identification of Di-(2ethylhexyl)phthalate compound from seeds of
Abrusprecatorius can be done with this method) with a mobile phase of ethyl acetate and absolute ethyl alcohol to collect the pure compound, di-(2-ethylhexyl) phthalate. The purity of the isolated compound was checked on Thin layer chromatography plates. ${ }^{(19)}$

4. Sodium dodecyl sulphate-polyacrylamide gel electrophoresis (SDS-PAGE): SDS-PAGE gave the protein of interest. To determine the size of the protein, SDS-PAGE was performed using 12\% polyacrylamide as the resolving gel and 5\% polyacrylamide as the stacking gel and the bands were stained by silver staining method then the bands were visualized by gel documentation system. ${ }^{(11)}$ The molecular weight of Agglutinin was $134 \mathrm{kDa}$ yielded peptides of approximately $33 \mathrm{kDa}$ and $29 \mathrm{kDa}$ respectively from SDS-PAGE. ${ }^{(12)}$

In a study, for protein isolation, at least 10 seeds were grounded to a fine powder with mortar and pestle. $250 \mathrm{mg}$ of powder was homogenized with $500 \mu \mathrm{l}$ of protein extraction buffer $(0.0625 \mathrm{M}$ TrisHCl, $\mathrm{pH} 6.8$, $2 \%(\mathrm{w} / \mathrm{v}) \mathrm{SDS}, 5 \%(\mathrm{v} / \mathrm{v}) 2$ - mercaptoethanol, $10 \%(\mathrm{w} / \mathrm{v})$ glycerol, $0.002 \%$ (w/v) bromophenol blue). The extracts were transferred to an eppendorf tube, and incubated for 2hours. After incubation the extracts was suspended in a boiling water bath for 2 minute, allow to

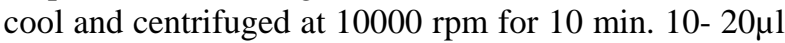
of supernatant was taken and separated by SDS-PAGE.

SDS - PAGE of seed protein was carried out in vertical slab gel discontinuous buffer system following the method of Laemmli (1970) using 13\% acrylamide gel concentration. A total volume of $10 \mu 1$ protein extract solution was loaded into each well andat $60 \mathrm{~V}$ electrophoresis was carried out until the bromophenol blue dye reaches the bottom of the gel. After electrophoresis, the gels were stained with staining solution consisting $0.2 \%(\mathrm{~W} / \mathrm{V})$ Comassie Brilliant Blue (CBB) R 250 dissolved in 50\% (V/V) methanol, $7 \%(\mathrm{~V} / \mathrm{V})$ acetic acid and $43 \%(\mathrm{~V} / \mathrm{V})$ distilled water over night at room temperature. Gels were destained in a solution containing $7 \%(\mathrm{~V} / \mathrm{V})$ acetic acid, $30 \%(\mathrm{~V} / \mathrm{V})$ ethanol and $63 \%(\mathrm{~V} / \mathrm{V})$ distilled water. Gels were shacked gently until the background of the gel became clear and protein bands were clearly visible. After de staining, the gels were photographed using gel documentation systems. Based on electrophoretic band spectra, Jaccard's similarity index (JSI) was calculated using the formula, JSI $=(2 \times$ No. of common bands)/Total no. of bands. The dendrogram was build based on this similarity index table using statistical software NTSYS- PC, version 2.01 (Rohlf, 1999). ${ }^{(23)}$

5. GC-MS analysis: GC-MS analysis was conveyed on a GC clarus 500 Perkin Elmer system and gas chromatograph interfaced to a mass spectrometer (GC-MS) instrument employing the following conditions: Column Elite-5MS fused capillary column $(30 \times 0.25 \mathrm{~mm} \times 0.25 \mu \mathrm{m} \mathrm{df})$ composed of 5\% Diphenyl / 95\% Dimethyl poly siloxane. Helium (99.999\%) was used as carrier gas at a 
constant flow of $1 \mathrm{ml}$ per min and injection volume of $2 \mu \mathrm{l}$ was adopted with a split ratio of 10:1. The injected sample was detected by Turbo mass gold detector (Perkin Elmer) with the aid of Turbomass 5.2 software. During the 36 minute GC extraction process, the oven temperature was programmed from of $110^{\circ} \mathrm{C}$ with an increment of $10^{\circ} \mathrm{C} / \mathrm{min}$ up to $200^{\circ} \mathrm{C}$, then $5^{\circ} \mathrm{C} / \mathrm{min}$ upto $280^{\circ} \mathrm{C}$ with 9 minutes hold. The injector temperature was set at $250^{\circ} \mathrm{C}$ (mass analyzer). Other parameters which was involved in the operation of Clarus 500MS, was also standardized (Inlet line temperature: $200^{\circ}$ C; source temperature: $200^{\circ} \mathrm{C}$ ). Mass spectra were taken at $70 \mathrm{eV}$ and fragments from $45-450 \mathrm{Da}$. The MS detection was completed in 36 minutes. The detection employed the NIST (National Institute of Standards and Technology) - Year 2005 library. ${ }^{(20)}$

6. Scanning electron microscope (SEM) analysis: The synthesis of silver nanoparticles from leaves of Abrusprecatorius can be done using Scanning electron microscope by using Hitachi S-4500 SEM Machine. Thin films were prepared on a carboncoated copper grid by just dropping a very small volume of the sample on the grid, extra solution was removed using a blotting paper and then the film was allowed to dry on the SEM grid.

a. EDAX measurements: The drop of leaf extract with reduced silver nanoparticles was dried on a film coated with carbon and EDAX analysis was performed on Hitachi S-3400N SEM instrument which was equipped with thermo EDAX attachments.

b. AFM measurements: The silver nanoparticles were visualized with an atomic force microscope which was extracted through the above protocol. A thin film of the sample prepared on a glass on the slide was allowed to dry for $5 \mathrm{~min}$ and the slides were then scanned with the AFM (Nano SurfAG, Switzerland, Product: BTO 2089, BRO).(21)

\section{Forensic Significance}

Abrusprecatorius is a very toxic plant and used for homicidal and suicidal purposes. ${ }^{(25)}$ The Gunja seed contains number of chemical constituents like steroid, triterpenoides, proteins, amino acids, alkaloids etc., among which an albumotoxin, abrin (a highly toxic protein) is considered the main responsible constituent for the poisonous effect of Abrusprecatorius Linn. The fatal dose for human is $1-2$ seeds or $0.1-1 \mu \mathrm{g} / \mathrm{kg}$ with a fatal period of 3-5 days. The seeds of Gunja are often used criminally for killing cattle where the seeds are powdered and made into a paste, with which the darts or arrows are dressed. ${ }^{(26)}$ Seeds and foliage are all poisonous. Clinicaltoxicosis reflects primary damage to the gastrointestinal tract and includes violent gastroenteritis followed by weakness and death (Cheeke \& Shull 1985; Galey 1996; Adedapo 2002). Abrin is present in the leaf and is known to have action on hyperactivity of the system (Burkill 1995). ${ }^{(27)}$ Abrus poisoning generally causes severe vomiting and abdominal pain, bloody diarrhoea and convulsions are the characteristic of abrus poisoning. Altered sensorium with depression of central nervous system also appears to be characteristic features. In rare cases, raised ICP and papilledema as manifestations of abrus poisoning had also been reported. ${ }^{(29)}$ Death in this situation is due to multi system organ failure as cellular protein synthesis is disrupted throughout the body. There are a few reported cases of abrin causing acute demyelinating encephalitis. ${ }^{(30)}$ Toxicological analysis is generally not helpful in cases of abrus poisoning, but thin layer chromatography in some cases did correspond to the chromatographic result on the patient's serum utilizing the seed extract and confirming that the patient had consumed abrus seeds. Treatment of abrus poisoning comprises timely decontamination by stomach wash and institution of supportive measures, although there is no antidote, but some investigators mention an antiserum ("anti-abrin" or "jequiritol") that used to be available in the past. There is no evidence to suggest that such an antiserum was ever available in India, or that it was ever tried. ${ }^{(28)}$

The reorganization of poisoning during life is a matter of the first important, both from the point of view of the medical jurist and as a forensic crime scene investigator which helps in solving the crime and searching the poisoning- plant materials on crime spot. On crime spot, forensic connoisseur can get evidence related to accidental, suicidal or homicidal poisoning by poisonous plants like parts of plants, spot of crime like forest/garden, symptoms of poisoning can help to direct the investigation of right path. On the basis of plant origin toxicity forensic team can tell whether it is suicide, homicide or accident. ${ }^{(25)}$

\section{Conclusion}

Abrusprecatorius is considered as a potent source of unique natural products for development of medicines or drugs against various harmful diseases. The roots, seeds and leaves are used in traditional folklore medicine. The plant Abrus precatorius is used in Ayurveda, Folk, Homeopathy, Sidha, Tibetian and Unani. There are many pharmacological activities shown by this plant. There are many techniques which are introduced to find out the chemical constituents which are present in Abrus Precatorius plant. Abrus seeds contain the toxic lectins, namely abrin (ABR)A-D which is fatal to humans. Treatment of abrus poisoning comprises timely decontamination by stomach wash and institution of supportive measures. It is essential to take cognizance of the fact that overuse or abuse of the medicinal constituents of plants can cause danger.

\section{References}

1. P. Prabha M., P. Perumal C., M. Kumar P., S S., M S., K Sampath R., Pharmacological activities of Abrus 
precatorius (L.) seeds, International Journal of Pharmaceutical and Medicinal Research,2015;3(2):195200.

2. Chaudhari SK., (chulet)Sharma R., Pawar SP., Kashikar AV., Pharmacological activities of Abrusprecatorius Linn. - A Review, International Journal of Ayurvedic and Herbal Medicine, 2:2(2012)336:348.

3. Bhatia M., NA S., Gupta S., Abrus Precatorius ( $L$.): An Evaluation of Traditional Herb, Indo American Journal of Pharmaceutical Research, 2013 ISSN NO: 2231-6876.

4. Ragasa YC., Lorena SG., Mandia HE., Raga DD., Shen C., Chemical constituents of Abrusprecatorius, American Journal of Essential Oils and Natural Products 2013;1(2):7-10.

5. Chandraker SK., Sharma N., ABRUS PRECATORIUS L. An important medicinal plant: a review, international journal of pharmaceutical research and bio-science, 2014; Volume 3(4): 657-670.

6. Kareppa MB., Phytochemical and Antimicrobial studies of Abrusprecatorius $L$.

7. Nabar M., Pimpalgaonkar PB., Laddha KS., Studies On Sodhana Prakriya Of Gunja (Abrus Precatorius Linn.) Seeds, Indian Journal Of Traditional Knowledge Vol. 10(4), October 2011,pp.693-696.

8. John De Britto A., Benjamin JeyaRathna Kumar P., Herin Sheeba Gracelin D., Separation of phytochemicals from abrus precatorius using TLC and HPTLC techniques, International Journal of Institutional Pharmacy and Life Sciences 4(2): March-April 2014.(ISSN): 2249-6807.

9. Bapat PS., Sane TR., Bio-analytical studies on the process of detoxification and safety evaluation of aconitum laciniatum and abrus precatorius for use in ayurvedic preparations, International Journal of Pharmaceutical Sciences And Research, 2012; Vol. 3(3):914-921.

10. Gupta J., Gupta M., Isolation and characterization of flavonoid from leaves of Abrusprecatorius, International journal of current research in chemistry and pharmaceutical sciences(p-ISSN: 2348-5213: e-ISSN: 2348-5221).

11. Prasad S., Bhutia KS., Isolation and characterization of lectins from red seeds of "Abrusprecatorius", National Institute of Technology Rourkela Odisha.

12. Mishra A., Bhutia KS., "Isolation and characterization of lectins from white seeds of "Abrusprecatorius", National Institute of Technology Rourkela Odisha.

13. Ross AI., Abrusprecatorius L., Medicinal Plants of the World, vol. 1: Chemical Constituents, Traditional and Modern Medicinal Uses, 2nd edition.

14. Malele NC., Lang'at-Thoruwa CC., Guantai NA., Chhabra CS., A New Pterocarpan From The Leaves of Abrus Precatorius L., Journal of Medicinal Plants Research,Vol.9(27), pp.749-754, 17 July,2015.

15. Garaniya N., Bapodra A., Ethno Botanical and phytopharmacological potential of abrus precatorius L.: A review, Asian Pacific Journal of Tropical Biomedicine.

16. Lebri M., Tilaoui M., Bahi C., Achibat H., Akhramez S., Fofie NBY., Gnahoue G., Lagou MS., Zirihi NG., Coulibaly A., Zyad A., Hafid A., Khouili M., Phytochemical Analysis And In Vitro Anticancer effect Of Aqueous Extract Of Abrus Precatorius Linn, Scholars Research Library,2015,7(8):112-117.ISSN 0975-413X.

17. Mensah YA., Bonsu SA., Fleischer CT., Investigation Of The Bronchodilator Activity Of Arbus Precatorius, Volume 6,issue 2,January-February 2011; Article-003.

18. Gul ZM., Ahmad F., Kondapi KA., Qureshi AI., Ghazi AI., Antioxidant and Antiproliferative Activities of
Abrusprecatorius Leaf Extracts-An In Vitro Study, BMC Complementary And Alternative Medicine, 2013

19. Abbassy AM., Masoud AS., Nassar KMA., In vitro antibacterial activity and phytochemical analysis of abrus precatorius Linn.

20. Krishnaveni M., Nandhini N., Dhanalakshmi R., A Study on phytochemicals, Fatty acid Analysis and Antimicrobial Activity of Abrus Precatorius Linn Seeds, International Journal of Pharmaceutical Sciences Review and Research. August 2014.

21. Gaddala B., Nataru S., Synthesis, characterization and evaluation of silver nanoparticles through leaves of Abrusprecatorius L.: an important medicinal plant, (2015) 5:99-104.

22. Ogbuehi HI., Ebong OO., Obianime WA., A Preliminary Study on the Effect of Abrusprecatorius Linn on Reproductive Parametersin Female Rattusnorvegicus, Wistar Strain, European Journal of Medicinal Plants,7(3):156-166, 2015, Article no.EJMP.2015.078.

23. John De Britto A., Benjamin Jeya Rathna Kumar P., Herin Sheeba Gracelin D., Genetic characterization of Abrusprecatorius L. varieties using SDS-PAGE,5(3):263269.

24. Solanki A., Savari M., Pharmacognosy, Phytochemistry and Pharmacology of Abrus Precatorius Leaf: A review, International Journal of Pharmaceutical Sciences Review and Research, Volume 13, Issue 2, March - April 2012; Article-016, ISSN 0976 - 044X.

25. Khajja SB., Sharma M., Singh R., Mathur GK., Forensic Study of Indian Toxicological Plants as Botanical Weapon (BW): A Review, Environment Analytic Toxicology 2011, 1:4.

26. Roy S., Acharya R., Shukla V J., Shodhana (Processing)Of Gunja (Abrusprecatorius Linn.) Seeds with Godugdha (Cow's milk); a pharmaceutical analysis, International Journal of Ayurvedic Medicine, 2012,3(2),68-75,ISSN: 0976-5921.

27. Adedapo AA., Omoloye AO., Ohore GO., Studies on the toxicity of an aqueous extract of theleaves of Abrusprecatorius in rats, Onderstepoort Journal of Veterinary Research,74:31-36 (2007).

28. VV Pillay, PV Bhagyanathan, R Krishnaprasad, RR Rajesh, N Vishnupriya Poisoning due to White Seed Variety of Abrus Precatorius: A case report, Vol. 53,April 2005.

29. Subhramanyan D., DKS., Mathew J., Raj M., An unusual manifestation of Abrus precatorius poisoning: A report of two cases, Clinical Toxicology (2008) 46, 173-175,ISSN: 1556-3650.

30. Jang HD., Nelson SL., The Red Seed: Abrus Precatorius. 